\title{
Nicotine Improves Working Memory Span Capacity in Rats Following Sub-Chronic Ketamine Exposure
}

\author{
Samantha L Rushforth', Thomas Steckler² and Mohammed Shoaib*,' \\ IInstitute of Neuroscience, Newcastle University, Newcastle upon Tyne, Newcastle, UK; ${ }^{2}$ Janssen Research \& Development, Beerse, Belgium
}

Ketamine, an NMDA-receptor antagonist, produces cognitive deficits in humans in a battery of tasks involving attention and memory. Nicotine can enhance various indices of cognitive performance, including working memory span capacity measured using the odor span task (OST). This study examined the effects of a sub-chronic ketamine treatment to model cognitive deficits associated with schizophrenia, and to evaluate the effectiveness of nicotine, antipsychotic clozapine, and the novel mGlu2/3 agonist, LY404039, in restoring OST performance. Male hooded Lister rats were trained in the OST, a working memory task involving detection of a novel odor from an increasing number of presented odors until they exhibited asymptotic levels of stable performance. Sub-chronic ketamine exposure (10 and $30 \mathrm{mg} / \mathrm{kg}$ i.p. for 5 consecutive days) produced a dose-dependent impairment that was stable beyond 14 days following exposure. In one cohort, administration of graded doses of nicotine $(0.025-0.1 \mathrm{mg} / \mathrm{kg}$ ) acutely restored the performance in ketamine-treated animals, while significant improvements in odor span were observed in control subjects. In a second cohort of rats, acute tests with clozapine $(1-10 \mathrm{mg} / \mathrm{kg})$ and LY404039 $(0.3-10 \mathrm{mg} / \mathrm{kg})$ failed to reverse ketamine-induced deficits in doses that were observed to impair performance in the control groups. These data suggest that sub-chronic ketamine exposure in the OST presents a valuable method to examine novel treatments to restore cognitive impairments associated with neuropsychiatric disorders such as schizophrenia. Moreover, it highlights a central role for neuronal nicotinic receptors as viable targets for intervention that may be useful adjuncts to the currently prescribed anti-psychotics.

Neuropsychopharmacology (20II) 36, 2774-278I; doi:10.1038/npp.20II.224; published online 28 September 20II

Keywords: odor span task; ketamine; nicotine; LY404039; clozapine; working memory

\section{INTRODUCTION}

Schizophrenia is a debilitating disorder affecting approximately $1 \%$ of the population: a multi-faceted disease with wide-ranging symptoms that comprise positive (auditory hallucinations, disorganized and deluded thoughts), negative (flattening of affect, apathy, and anhedonia), and cognitive deficits (attention and memory) (Perala et al, 2007). These cognitive deficits are considered to be the core disabling feature of the disease, and yet remain inadequately treated by pharmacological or behavioral therapeutic approaches (Javitt, 1999; Weinberger and Gallhofer, 1997). Of the various cognitive domains impaired (Buchanan et al, 2005), working memory span capacity deficits have been reported in schizophrenic patients (Gold et al, 2010).

*Correspondence: Dr M Shoaib, Psychobiology Research Laboratories, Institute of Neuroscience, Newcastle University, Newcastle Medical School, Newcastle upon Tyne, Framlington Place, Newcastle NE2 4HH, UK, Tel: + 44 19| 222 7839, Fax: + 44 191 2225227 ,

E-mail: mohammed.shoaib@newcastle.ac.uk

Received I March 201 I; revised 16 August 2011; accepted 17 August 2011
Dysregulation of glutamatergic transmission is proposed to have a crucial role in cognition. In both animals and humans, sub-anesthetic doses $(0.1 \mathrm{mg} / \mathrm{kg})$ of NMDA-receptor antagonist phencyclidine can induce symptoms of schizophrenia, including negative and cognitive symptoms (Luby et al, 1959; Murray, 2002; Nabeshima et al, 2006). Ketamine is a less potent analog of phencyclidine with a shorter half-life (Anis et al, 1983). Thus, the psychotomimetic effects observed following acute sub-anesthetic doses are transient and reversible. Ketamine is thought to induce cognitive deficits by initially binding to NMDA receptors on pyramidal cells, which in turn causes disinhibition of GABA fast-spiking interneurons, producing a net increase of glutamatergic transmission, which acts to increase transmission at non-NMDA receptors such as AMPA and kainate, which in turn increases dopamine release in the prefrontal complex (PFC), which is thought to be responsible for causing cognitive deficits (Jedema and Moghddam, 1996; Moghaddam et al, 1997).

In healthy subjects, a sub-anesthetic dose of ketamine induces a wide range of symptoms that are indistinguishable from those present in schizophrenia (Krystal et al, 1994; Parwani et al, 2005). Krystal et al (1994) 
demonstrated that administration of ketamine ( 0.1 and $0.05 \mathrm{mg} / \mathrm{kg}$ ) to healthy subjects could dose-dependently induce positive, negative, and cognitive symptoms (Krystal et al, 1994). Schizophrenic patients also experienced exacerbated symptoms upon ketamine administration in a double-blind, placebo-controlled study (Malhotra et al, 1997). Likewise, 13 neuroleptic-free patients treated with sub-anesthetic ketamine experienced exacerbated psychotic symptoms and further cognitive impairment (Malhotra et al, 1997).

Despite the successful use of NMDA-receptor antagonists to model symptoms of schizophrenia, it is only recently that a glutamatergic compound has been tested for treatment of schizophrenia with any success. LY404039 is a highly selective agonist for metabotropic glutamate 2/3 (mGlu2/3) receptors developed by Eli Lilly, and currently is in Phase II clinical trials for treatment of schizophrenia. Patil et al (2007) carried out a double-blind, placebo-controlled study with LY2140023 (an oral pro-drug of LY404039) in patients with schizophrenia, using olanzapine as an active control. Patients treated with LY2140023 or olanzapine showed statistically significant improvement in both positive and negative symptoms when compared with placebo. However, a follow-up study revealed negative results, and so further research is necessary to elucidate whether there is a role for mGlu2/3 receptors in terms of treatment for cognitive deficits (Patil et al, 2007).

The odor span task (OST) is a non-spatial task that assesses the span capacity of working memory, which is not dependent on the hippocampus (Dudchenko et al, 2000a). In the OST, rats are trained to dig in bowls of scented woodchip for food rewards. Upon retrieval of the reward, another bowl containing a differently scented woodchip is added. The novel bowl is the only bowl baited and must be selected over the previously sampled bowl. With each correct response, another bowl is added to assess the number of odors that can be remembered by an individual rat in a given trial. The number of odors remembered (span) provides a measure of working memory span capacity.

We have previously used the OST to demonstrate that nicotine and specific nicotinic-receptor agonists can improve working memory span capacity in rats. When drugnaivve rats trained in the OST were administered nicotine $(0.05$ and $0.1 \mathrm{mg} / \mathrm{kg})$, the $\alpha 4 \beta 2$ agonist metanicotine, or the $\alpha 7$ agonist (compound $A$ ), all showed significant improvement in their working memory span capacity (Rushforth et al, 2010).

Nicotine, known primarily for its addictive properties, has proven beneficial effects on cognition in smokers (Atzori et al, 2008; Newhouse et al, 2004) and non-smokers (Foulds et al, 1996; Froeliger et al, 2009). As the vast majority $(\sim 80 \%)$ of schizophrenic patients smoke compared with the general population $(\sim 30 \%)$, it has been proposed that schizophrenic smokers may self-medicate with nicotine to ameliorate the deficits in cognition (Bidzan, 2007; Zabala et al, 2009).

The present experiments aimed to assess whether subchronic exposure to ketamine presents a viable model to examine cognitive deficits on working memory span capacity associated with schizophrenia in rats. Using the OST, any impairment of working memory span capacity by ketamine was examined for restoration by acutely treating with nicotine. Comparisons with clozapine and the novel mGlu 2/3-receptor agonist LY404039 provided a translational perspective on ketamine-induced impairment from their relative efficacy to restore OST performance.

\section{MATERIALS AND METHODS}

\section{Animals}

Two cohorts of 24 male hooded Lister rats (Harlan, UK), each weighing approximately $175 \mathrm{~g}$ at the beginning of the training, were used. Animals were housed in groups of four under standard conditions (a temperature-regulated room with a 12-h light/dark cycle, lights on at 0700 hours). Rats were food-restricted at approximately 8 weeks for the duration of the study, with weights monitored daily and amount of food adjusted to allow for natural growth. Under this schedule, no animal showed a weight of less than $85 \%$ ad libitum body weight. Animals were permitted free access to water in the home cage and all testing was conducted in the light phase of the 12-h light/dark cycle. The experiment was carried out in accordance with the UK Animals (Scientific Procedures) Act, 1986.

\section{Equipment}

All training and testing were done on a wooden platform covered in black vinyl, $93-\mathrm{cm}$ square with a $5-\mathrm{cm}$ raised border. This was elevated $83 \mathrm{~cm}$ from the floor by placing on a table. The bowl locations were evenly spaced around the platform. Once the training began, the position of the platform and table was kept the same throughout. Opaque ceramic dishes were used to house the scented woodchip used for the task. The following 24 odors were used in the task: rosemary, mint, onion powder, oregano, cinnamon, thyme, mixed spice, chinese-5-spice, paprika, fenugreek, nutmeg, garlic powder, caraway seed, celery salt, tea leaves, ginger (ASDA own brand), cocoa powder, cumin, coffee powder, coriander, parsley, sage, dill, and lemon tea (Lift). All were Tesco-owned brands or Schwarz, except as indicated. Three grams of each odor was mixed with $100 \mathrm{~g}$ of woodchip and nine crushed Nestlé Cheerios (added to minimize the likelihood of the rat digging in the correct bowl through scent of the food reward).

\section{Shaping and Acquisition of the Non-Matching-to- Sample (NMTS) Rule}

Rats were handled for approximately 5 min daily during the week before the start of training. The initial training sessions took place in a cage on top of the platform. The rats were trained to dig in an unscented woodchip for a food reward (half a Nestlé Cheerio). Once they reliably started digging in the woodchip for the food reward, scented bowls were introduced. The animal dug in the first bowl, retrieved the food reward, and was then removed from the platform. The first bowl was relocated and a second differently scented bowl was added. The rat had to smell both odors and then dig in the bowl containing the novel odor, as this was the only bowl baited. Each rat took part in up to 10 trials per session for three sessions (time limited to $15 \mathrm{~min}$ ), 
until they had learned the NMTS rule. The odors used were chosen randomly each day from the 24 mentioned above using a random letter list. All animals were exposed to all 24 scents within the three sessions.

\section{OST Training}

In this phase, rats were introduced to the experimental platform, where they underwent one further day of NMTS training with only two bowls at a time. From then on, the span task proceeded as the NMTS task, but after a correct choice was made on the second bowl, an additional bowl containing a novel scent was added. This meant that the animal had to assess all three bowls and choose the third bowl. This was on the basis of scent alone, as all bowls were relocated to prevent spatial cues aiding the choice. This procedure was repeated until 10 bowls were present or the rat had spent $15 \mathrm{~min}$ on the platform. This was the case despite any errors in sample choice. If a mistake was made, the animal was removed from the platform, the bowls were relocated, and the animal was reintroduced. Once a correct choice was made, the rat was permitted to carry on to the next level. At this point, bowls were relocated but kept in reasonably close proximity (a half-OST: locations limited to numbers 1-12 on the OST board). This was done so that the animals learned more quickly (approximately four sessions) to sniff all odors before making a choice, rather than attempting to dig in every bowl. Following four half-OST sessions, animals took part in the full OST, in which bowls could be located in any of the 1-24 spaces, and the task was ended once a mistake was made. This continued for a further 9-10 sessions, until asymptotic performance was demonstrated. The main measured parameter in this task was the 'span': determined as the number of correct and consecutively chosen bowls minus 1 (as the first bowl generates no memory load). Other parameters measured included time to first sample and total time spent on the platform. Asymptotic performance was determined as achieving a span of 5 in at least two consecutive sessions and fluctuating within a minimum of 3 spans over four consecutive sessions based on the criteria outlined by Dudchenko et al (2000b). For example, 3554, 5756, and 8868 were all acceptable span patterns for four sessions.

\section{Probe Sessions}

In this study, at random points during the training sessions, the reward for a correct choice was dropped into the bowl after a correct choice was made. Animals still chose correctly in each case, indicating that they were responding to the olfactory cues provided, and not to the scent of the reward. Occasionally, bowls and scented woodchip were replaced during the trial to ensure that animals were not scent-marking and using this to identify the novel bowl.

\section{Sub-Chronic Exposure to Ketamine}

In both experiments, once the performance was stable, the rats were pseudo-randomized into performance-matched groups of eight (first cohort) or six (second cohort), and treated with vehicle or ketamine (10 or $30 \mathrm{mg} / \mathrm{kg}$ i.p.) daily for 5 consecutive days. At least 2 days were allowed following the last ketamine injection to ensure 'washout' before tests with nicotine or the antipsychotic compounds.

\section{Tests on OST}

Testing was conducted every third day, with a rest day for washout followed by a training session before retesting. On test days, the maximum number of bowls used was increased from 10 to 15 to allow for any enhancing effect of compounds tested to be revealed. In a randomized order, acute doses of nicotine $(0.025,0.05$, and $0.1 \mathrm{mg} / \mathrm{kg}$ s.c. $)$ were evaluated on the OST given 10 min before placement on the platform. The following day, the rats were rested to allow for 'washout' followed by retraining on the OST before the next test. Similarly, in the second experiment, tests were conducted with the atypical antipsychotic clozapine (1, 3, and $10 \mathrm{mg} / \mathrm{kg}$ i.p.) and the novel $\mathrm{mGlu} 2 / 3$ receptor agonist LY404039 (0.3, 1, 3, and $10 \mathrm{mg} / \mathrm{kg}$ s.c.) administered 45 and $30 \mathrm{~min}$ before testing, respectively. As before, doses of the antipsychotic compounds were tested acutely in a randomized sequence that occurred every third day, which allowed 'washout' of the test drug followed by retraining on the OST before the next test. In all the above tests, the experimenter was blinded to the dose of test compound being administered and the previous history of sub-chronic exposure.

\section{Statistical Analysis}

The odor span from each group of rats was analyzed by using a two-way, repeated-measures ANOVA with dose as the within-subject factor and ketamine treatment as the between-subjects factor. Differences between groups and comparisons from vehicle were calculated using Bonferroni post-hoc tests where appropriate. Statistical significance was defined at $p<0.05$. All analyses were performed using SPSS for Windows (SPSS Inc., V15.0).

\section{Drugs}

Ketamine (Sigma Aldrich, UK) was dissolved in water for injection and $\mathrm{pH}$ was adjusted to $\sim 6$ with $0.1 \mathrm{M} \mathrm{NaOH}$. In the preliminary experiment, 10 or $30 \mathrm{mg} / \mathrm{kg}$ doses were administered once daily for 5 consecutive days. In the second experiment, $10 \mathrm{mg} / \mathrm{kg}$ was used for all animals, as the first experiment revealed that this induced sufficient deficits in task performance. Nicotine hydrogen tartrate (Sigma Aldrich) was dissolved in water for injection and the $\mathrm{pH}$ was adjusted to 7 with $\mathrm{NaOH}$ solution. Nicotine in doses of $0.025,0.05$, or $0.1 \mathrm{mg} / \mathrm{kg}$ was administered s.c. $10 \mathrm{~min}$ before testing on the OST. Clozapine (Eli Lilly, synthesized by Janssen Pharmaceuticals, Belgium) was dissolved in $0.1 \mathrm{M} \mathrm{HCl}$, and then adjusted to a physiological $\mathrm{pH}$ of 7 . Clozapine in doses of 1,3 , and $10 \mathrm{mg} / \mathrm{kg}$ were given i.p. $45 \mathrm{~min}$ before testing on the OST. LY404039 (Eli Lilly, synthesized by Janssen Pharmaceuticals, Belgium) was dissolved in $\mathrm{NaOH}$ and $\mathrm{pH}$ was balanced to around 6 . LY404039 in doses of $0.3,1.0,3.0$, and $10.0 \mathrm{mg} / \mathrm{kg}$ were given $30 \mathrm{~min}$ before testing. Doses of both clozapine and LY404039 were based according to the pharmacokinetic parameters derived by Janssen Research \& Development, Beerse, Belgium and previously published literature 
(Abdul-Monim et al, 2006; Rorick-Kehn et al, 2007). All values were expressed as those of the base.

\section{RESULTS}

\section{Acquisition of the OST}

Animals were trained according to a NMTS rule for approximately four training sessions. They were then moved onto a half OST until they achieved a span of 5 (Figure 1). From here, they were trained in the full OST until asymptotic performance was demonstrated: a span of 5 on at least two consecutive sessions, which does not fluctuate more than 3 spans over four consecutive sessions (Figure 1).

\section{Ketamine Induces Deficits in OST Performance that Persist Over 21 Days}

Before sub-chronic treatment, the mean odor span for the whole group of rats was $6.9 \pm 0.3$ (mean \pm SEM of the five runs before treatment). The mean odor spans for control, ketamine $10 \mathrm{mg} / \mathrm{kg}$, and ketamine $30 \mathrm{mg} / \mathrm{kg}$ were $6.9 \pm 0.5$, $7.0 \pm 0.4$, and 6.9 \pm 0.6 , respectively. Animals were performance-matched to ensure no significant difference in the mean span between the experimental groups before treatment $(\mathrm{F}(2,21)=0.003$, n.s.). Ketamine treatment for 5 days with either 10 or $30 \mathrm{mg} / \mathrm{kg}$ dose resulted in a substantial impairment of odorspan detection $(\mathrm{F}(1,15)=372.6, p<0.001)$, as measured over 8 days following the last dose of ketamine (Figure 2).

\section{Nicotine $0.025,0.05$, and $0.1 \mathrm{mg} / \mathrm{kg}$ Dose-Dependently Enhance OST Performance in Both Control and Ketamine-Treated Animals}

Acute administration of nicotine at $0.025,0.05$, and $0.1 \mathrm{mg} / \mathrm{kg}$ produced a dose-dependent increase in task performance in both control and ketamine-treated animals $(\mathrm{F}(3,45)=28.2, p<0.001)$. These improvements are illustrated in Figure 3. There was no interaction between the two factors $(\mathrm{F}(6,45)=1.73$, n.s. $)$, suggesting that nicotine

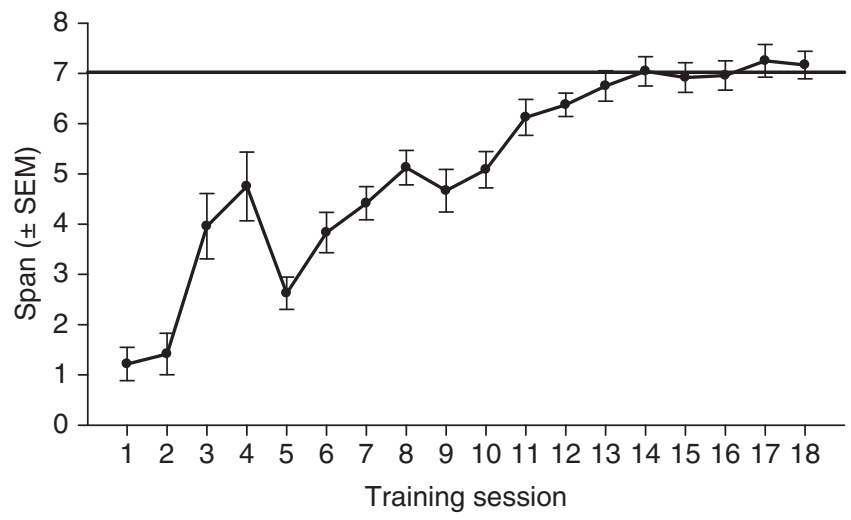

Figure I Acquisition of the OST $(n=24)$ over 18 training sessions, including 4 specific sessions each on the NMTS and $\frac{1}{2}$ OST stages and 10 sessions on the full task. The dashed line depicts the mean span attained by the group towards the final stages of training. Each data point depicts the mean \pm SEM. improved OST performance irrespective of pretreatment. The $0.1-\mathrm{mg} / \mathrm{kg}$ nicotine dose was the most effective in enhancing performance by improving the span by 4 in both vehicle- and ketamine-treated groups.

\section{Neither Clozapine Nor LY404039 Reverses Ketamine-Induced Deficits in the OST}

Five test sessions following ketamine exposure confirmed impairments in odor span detection, being reduced to $3.3 \pm 0.8$, compared with the control group that exhibited a baseline mean span of $8.0 \pm 1.2$. Treatment with acute

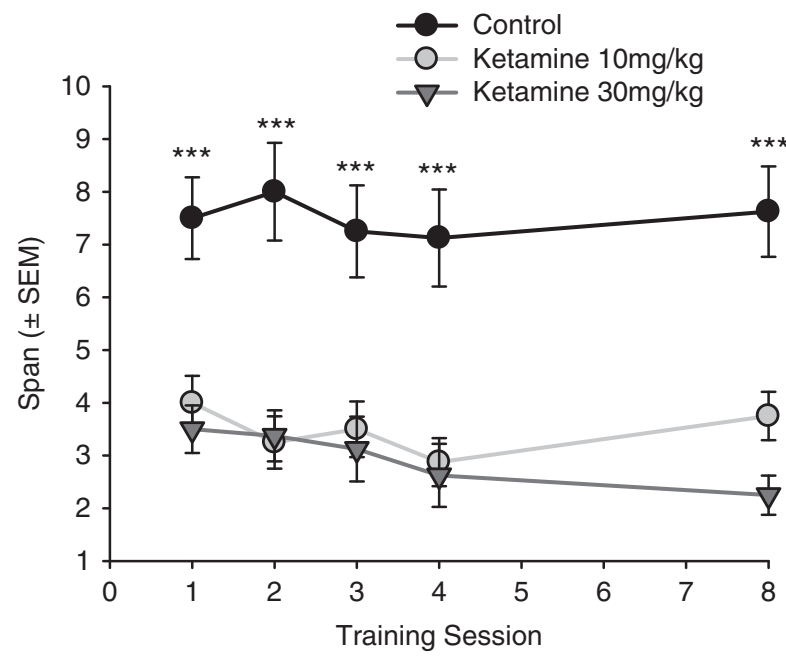

Figure 2 Treatment with sub-chronic ketamine at both 10 and $30 \mathrm{mg} / \mathrm{kg}$ induced significant deficits in OST task performance stable over 8 days $(n=8)$. **** denotes statistical significance from the vehicle-treated group $(p<0.00 \mathrm{I})$. Each data point depicts the mean \pm SEM.

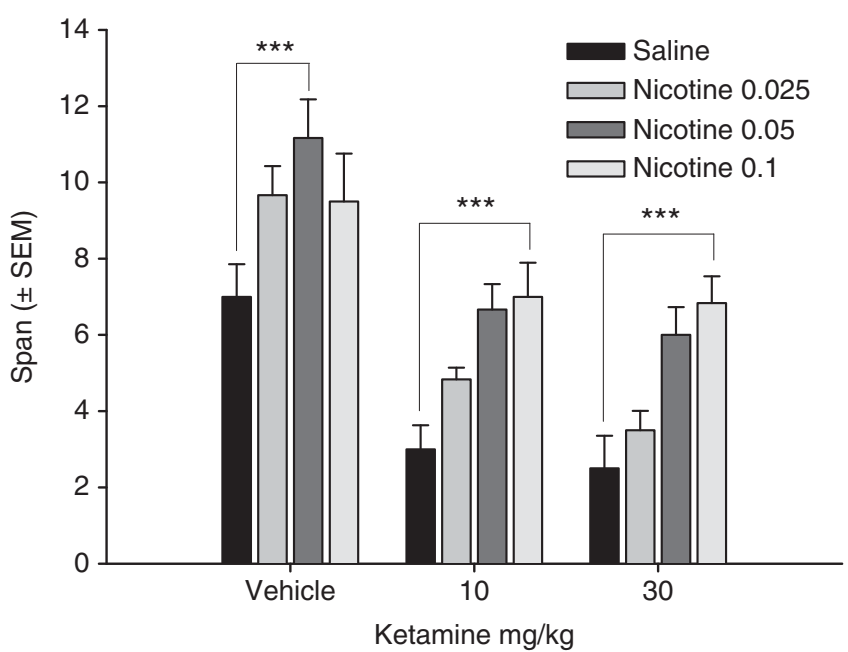

Figure 3 The effect of two doses of ketamine (10 and $30 \mathrm{mg} / \mathrm{kg}$ ) on span length in the OST. Both groups of animals $(n=8)$ treated with ketamine exhibited significantly decreased span length when compared with control animals. This deficit in span length was reversed by ketamine administration in a dose-dependent manner. Nicotine also improves span length in control animals. Each bar depicts the mean \pm SEM. **** denotes statistical significance from vehicle treatment $(p<0.00 \mathrm{I})$. 

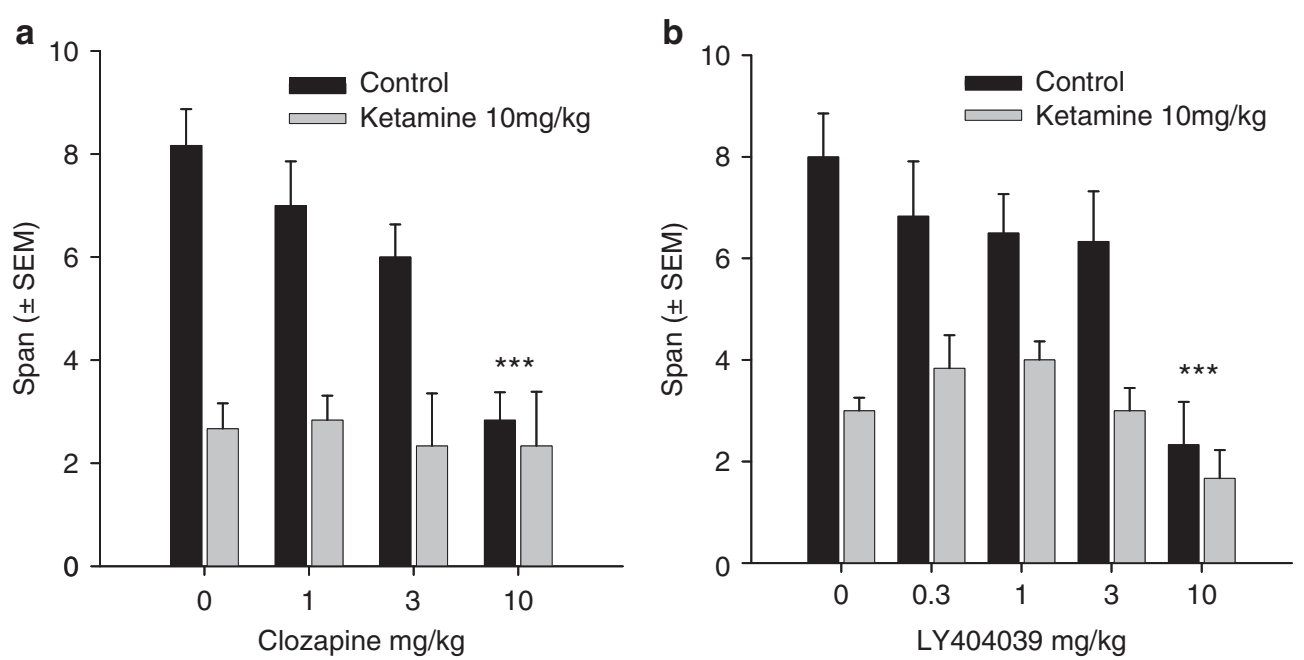

Figure 4 Neither clozapine (a) nor LY404039 (b) significantly reverses deficits in OST task performance. Both produce significant deficits in performance of control animals in a dose-dependent manner ( $n=6 /$ group). Each data point depicts the mean \pm SEM. **** denotes statistical significance between groups $(p<0.00$ I). ***** denotes statistical significance $(p<0.0$ I).

doses of clozapine $(1,3$, and $10 \mathrm{mg} / \mathrm{kg})$ or vehicle impaired the performance of control animals, but ketamine-treated animals were unaffected (Figure 4). A two-way repeatedmeasures ANOVA revealed that clozapine impaired OST performance $(\mathrm{F}(3,30)=6.2, p<0.01)$, which interacted with ketamine exposure $(\mathrm{F}(3,30)=4.6, p<0.05)$. When analyzed within the group using a one-way ANOVA for repeated measures, clozapine had no significant effect on OST performance in animals that were previously exposed to ketamine $(F(3,23)=0.095$, n.s. $)$, but caused a dose-dependent impairment in performance of control animals $(\mathrm{F}(3,23)=10.9, p<0.001)$.

In another set of animals, ketamine exposure also impaired performance, reducing the span to $3.0 \pm 0.7$, compared with the control group that exhibited baseline span levels of $7.7 \pm 0.6$. Treatment with acute doses of LY404039 $(0.3,1,3$, or $10 \mathrm{mg} / \mathrm{kg})$ or vehicle did not improve the performance; in fact the highest dose impaired the performance (Figure 4). A two-way repeated-measures ANOVA revealed LY404039 to have a significant effect on OST performance $(\mathrm{F}(4,40)=12.3, p<0.001)$, along with a significant interaction with ketamine $(\mathrm{F}(4,40)=3.5$, $p<0.01$ ). Further analysis using a one-way ANOVA to compare the effects of LY404039 on each subgroup revealed LY404039 to cause a dose-dependent impairment in the performance of control animals $(\mathrm{F}(4,29)=5.60, p<0.01)$, and a small but significant effect of LY404039 was seen in the ketamine-treated animals $(\mathrm{F}(4,29)=38, p<0.05)$. However, post-hoc analysis did not reveal significant effects of LY404039 when compared with vehicle treatment (Figure 4).

\section{DISCUSSION}

Sub-chronic ketamine exposure produced a long-lasting impairment of OST performance in rats; the animals remained stable for up to 21 days from treatment. The most significant finding that emerged from this study was the relative efficacy of nicotine in improving the odor span achieved in both control and ketamine-treated rats, improvements that were dose-related, and a maximal effect achieved at the $0.05-\mathrm{mg} / \mathrm{kg}$ dose. Under these conditions, clozapine with the mGlu2/3-receptor agonist LY404039 were not effective in restoring performance in the ketaminetreated rats, and remarkably impaired the performance in control animals.

The persistence of cognitive deficits produced by subchronic exposure to sub-anesthetic doses of ketamine is not well documented. However, Becker et al (2003) injected rats with $30 \mathrm{mg} / \mathrm{kg}$ ketamine i.p. daily for 5 days; the same regimen as employed in this study. They reported that 4 weeks after the last injection of ketamine, glutamate binding in the PFC was decreased by $25 \%$ but remained unchanged in both the hippocampus and striatum (Becker et al, 2003). This might explain the long-lasting effects of treatment with ketamine in this study.

Ketamine impairs cognition in both humans and animals (Becker et al, 2003; Buccafusco and Terry, 2009; Ghoneim et al, 1985; Krystal et al, 1994, 2005; Malhotra et al, 1996, 1997; Newcomer et al, 1999; Verma and Moghaddam, 1996). Verma and Moghaddam (1996) treated rats with ketamine 10,20 , and $30 \mathrm{mg} / \mathrm{kg}$ i.p. before a spatial/non spatial shortterm memory task, which resulted in significant deficits in performance (Verma and Moghaddam, 1996). More recently, Buccafasco and Terry (2009) gave sub-anesthetic doses of ketamine to monkeys trained in a computerassisted delayed response task. Ketamine reduced accuracy in performance but did not affect the processing speed. This effect was also fully reversed by the $\alpha 7 \mathrm{nAChR}$ partial agonist DMXB-A ([3-[(3E)-3-[(2,4-dimethoxyphenyl) methylidene]-5,6-dihydro-4H-pyridin-2-yl]pyridine]) (Buccafusco and Terry, 2009). These basic findings translate well; Malhotra et al (1996) administered sub-anesthetic doses of ketamine to 15 healthy volunteers, and observed an impaired performance on various measures of attention and memory (Malhotra et al, 1996). In a later study, this group also reported on ketamine further impairing the cognitive performance in schizophrenic patients, as well as exacerbating symptoms of psychosis (Malhotra et al, 1997). These clinical findings agree with the present observed results 
suggesting that ketamine exposure in the OST appears to be a valuable and clinically relevant model for modelling cognitive deficits in rodents. However, in a double-blind, crossover clinical trial, though DMXB-A improved attention and working memory in the first treatment arm, the MATRICS cognitive measures showed no significant difference over the three treatment arms when compared with placebo (Freedman et al, 2008).

Nicotine can enhance cognition in smokers, non-smokers, laboratory animals previously exposed to nicotine, and in animals that are nicotine-naive (for a review, see Levin et $a l, 2006)$. Nicotine has also been shown to enhance cognitive function in schizophrenic patients (Barr et al, 2008; Jacobsen et al, 2004; Smith et al, 2002, 2006). Similarly, George et al (2002) demonstrated that smoking abstinence significantly reduced visuospatial working memory in schizophrenic smokers but not in control smokers. The schizophrenic smokers also experienced a beneficial effect on spatial working memory after smoking a cigarette; this effect was not observed in control subjects (George et al, 2002). These results translate well with the present observations in ketamine-treated rats, and support previous reports on improvements with nicotine in noncompromised subjects (Rushforth et al, 2010).

Nicotine has previously been reported to improve cognitive performance specifically in animal models of working memory. Levin et al $(1997,1998)$ examined the effect of both acute and chronic nicotine administration on working and reference memory in a 16 -arm radial maze. In both cases, nicotine caused significant improvements in working, but not in reference memory. In acute tests, nicotine administration was also shown to significantly attenuate impairments produced by mecamylamine (Levin et al, 1996, 1997). Further support comes from a study by Young et al (2007a) in which nicotine could restore OST performance in transgenic mice (Young et al, 2007a). Further experiments with repeated nicotine tests will inform on how persistent these improvements are on the working memory span capacity.

From a neurobiological perspective, Dudchenko et al $(2000 a, b)$ discovered that the non-spatial span capacity of working memory in rats is not reliant on an intact hippocampus; hippocampal lesions did not impair OST performance. Several studies have confirmed a significant contribution of the medial PFC (mPFC) in an olfactory serial reversal and delayed alternation tasks (Kinoshita et al, 2008; Yoon et al, 2008). The mPFC of rodents is considered to be functionally homologous to the primate dorsolateral PFC, which also has a role in attention and working memory (Dalley et al, 2004; Groenewegen and Uylings, 2000). Interestingly, Dade et al (2001) have shown that the dorsolateral PFC is involved in olfactory working memory in humans. Using positron emission tomography to measure cerebral blood flow changes in 12 volunteers during an olfactory working memory task, they observed a significant activation of the PFC, specifically the dorsolateral and ventrolateral frontal cortex (Dade et al, 2001; Dalley et al, 2004). This and other animal studies suggest that despite the involvement of multiple brain regions in cognition, the modulatory effect of nicotine on the nonspatial span capacity of working memory in the work presented here is likely to be mediated through the nAChRs in the PFC (Granon et al, 1995; Levin, 1992). In further support of this, Turchi and Sarter (2000), using the rodent OST, found a significant contribution of cholinergic fibers in the PFC to the span capacity of working memory function and attention. Infusion of ${ }^{192} \mathrm{IgG}$-saporin into the basal forebrain resulted in an $80 \%$ reduction in density of frontodorsal acetlycholinesterase-positive fibers (Turchi and Sarter, 2000), which correlated significantly with a decline in olfactory span performance. These studies highlight the importance of both PFC involvement and the necessity of cholinergic processes in olfactory working memory span capacity. An enhanced activation as a result of nicotine administration may therefore enhance olfactory working memory and attention in both compromised and normal rodents by increasing cholinergic input to the mPFC, thereby increasing the excitatory synaptic strength (Laroche et al, 1990, 2000). This finding is supported by Young et al (2007b), who found that $\alpha 7$ nAChR knockout mice were impaired on the OST, though they suggested that this difference was largely a result of impaired attention, rather than working memory, required to maintain an adequate span capacity.

In this set of experiments, one objective was to compare the effects of nicotine with those of clozapine, which is known for its clinical efficacy against positive symptoms, for its ability to restore ketamine-induced deficits in the OST. Clozapine has been reported to reverse deficits on various cognitive domains; clozapine restored the FG1742induced delayed memory deficits in monkeys (Murphy et al, 1997), attentional deficits produced by blockade of NMDA in the PFC of rats (Baviera et al, 2008), and phencyclidine-induced deficits on reversal learning in rats (Abdul-Monim et al, 2006). While these latter reports highlight the effects of clozapine on attentional and executive function, other studies focusing on spatial working memory generally have been less conclusive, highlighting the lack of translation to the clinical situation. Levin and Christopher (2006) found that clozapine impaired rather than improved spatial working memory in the rat neonatal hippocampal lesion model of schizophrenia (Levin and Christopher, 2006). The present finding, that clozapine was not effective against ketamine-induced deficits and impaired performance in control subjects in the OST, supports previous findings (Addy and Levin, 2002; Gray et al, 2009; Levin and Rezvani, 2006; Pocivavsek et al, 2006). This inconsistency of clozapine on working memory is also apparent clinically (Meltzer and McGurk, 1999; Rosenheck et al, 1999).

Clinically, clozapine is administered repeatedly, which takes several weeks before minimal effects on cognitive performance are observed. Clozapine's inability to enhance performance in the OST might be due to experimental design; all antipsychotics given clinically do not display immediate effects. In future, repeated administration would perhaps allow clozapine to be more effective.

LY404039, like clozapine, was also ineffective in restoring ketamine-induced non-spatial span capacity of working memory deficits. However, if the dose of ketamine used to induce deficits was reduced, perhaps a significant effect of LY404039 might have become apparent. Additionally, as with most antipsychotics, Patil et al (2007) report a significant clinical effect of LY404039 at week 4 of the 
treatment (Patil et al, 2007). This suggests that acute doses might be insufficient to overcome deficits.

In summary, ketamine has been shown to induce significant deficits in non-spatial working memory performance in the OST. This was fully reversed with acute doses of nicotine, which also improved the performance in noncompromised subjects. Neither clozapine nor LY404039 restored the performance in ketamine-treated rats tested on the OST. Taken together with the nicotine data, the present findings support the use of ketamine in the OST to model cognitive deficits associated with schizophrenia, and also suggest that nicotinic agonists might be useful as an adjunct therapy to the currently prescribed anti-psychotics.

\section{ACKNOWLEDGEMENTS}

This research was supported by a research studentship grant awarded by Janssen Research \& Development, Beerse, Belgium.

\section{DISCLOSURE}

The authors declare no conflict of interest.

\section{REFERENCES}

Abdul-Monim Z, Reynolds GP, Neill JC (2006). The effect of atypical and classical antipsychotics on sub-chronic PCPinduced cognitive deficits in a reversal-learning paradigm. Behav Brain Res 169: 263-273.

Addy N, Levin E (2002). Nicotine interactions with haloperidol, clozapine and risperidone and working memory function in rats. Neuropsychopharmacology 27: 534-541.

Anis N, Berry S, Burton N, Lodge D (1983). The dissociative anaesthetics, ketamine and phencyclidine, selectively reduce excitation of central mammalian neurones by N-methylaspartate. $\mathrm{Br} J$ Pharmacol 79: 565-575.

Atzori G, Lemmonds CA, Kotler ML, Durcan MJ, Boyle J (2008). Efficacy of a nicotine $(4 \mathrm{mg})$-containing lozenge on the cognitive impairment of nicotine withdrawal. J Clin Psychopharmacol 28: 667-674.

Barr R, Culhane M, Jubelt L (2008). The effects of transdermal nicotine on cognition in nonsmokers with schizophrenia and nonpsychiatric controls. Neuropsychopharmacology 33: 480-490.

Baviera M, Invernizzi RW, Carli M (2008). Haloperidol and clozapine have dissociable effects in a model of attentional performance deficits induced by blockade of NMDA receptors in the mPFC. Psychopharmacology (Berl) 196: 269-280.

Becker A, Peters B, Schroeder H (2003). Ketamine-induced changes in rat behaviour: a possible animal model of schizophrenia. Prog Neuropsychopharmacol Biol Psychiatry 27: 687-700.

Bidzan L (2007). A review of the effects of nicotine on schizophrenia. Psychiatr Pol 41: 737-744.

Buccafusco JJ, Terry Jr AV (2009). A reversible model of the cognitive impairment associated with schizophrenia in monkeys: potential therapeutic effects of two nicotinic acetylcholine receptor agonists. Biochem Pharmacol 78: 852-862.

Buchanan RW, Davis M, Goff D, Green MF, Keefe RS, Leon AC et al (2005). A summary of the FDA-NIMH-MATRICS workshop on clinical trial design for neurocognitive drugs for schizophrenia. Schizophr Bull 31: 5-19.

Dade L, Zatorre R, Evans A, Jones-Gotman M (2001). Working memory in another dimension: functional imaging of human olfactory working memory. NeuroImage 14: 650-660.
Dalley J, Cardinal R, Robbins T (2004). Prefrontal executive and cognitive functions in rodents: neural and neurochemical substrates. Neurosci Biobehav Rev 28: 771-784.

Dudchenko PA, Wood ER, Eichenbaum H (2000a). Neurotoxic hippocampal lesions have no effect on odor span and little effect on odor recognition memory but produce significant impairments on spatial span, recognition and alternation. J Neurosci 20: 2964-2977.

Dudchenko PA, Wood ER, Eichenbaum H (2000b). Neurotoxic hippocampal lesions have no effect on odor span and little effect on odor recognition memory but produce significant impairments on spatial span, recognition, and alternation. J Neurosci 20: 2964-2977.

Foulds J, Stapleton J, Swettenham J, Bell N, McSorley K, Russell MA (1996). Cognitive performance effects of subcutaneous nicotine in smokers and never-smokers. Psychopharmacology (Berl) 127: 31-38.

Freedman R, Olincy A, Buchanan RW, Harris JG, Gold JM, Johnson $\mathrm{L}$ et al (2008). Initial phase 2 trial of a nicotinic agonist in schizophrenia. Am J Psychiatry 165: 1040-1047.

Froeliger B, Gilbert DG, McClernon FJ (2009). Effects of nicotine on novelty detection and memory recognition performance: double-blind, placebo-controlled studies of smokers and nonsmokers. Psychopharmacology (Berl) 205: 625-633.

George T, Vessicchio J, Termine A, Sahady D (2002). Effects of smoking abstinence on visuospatial working memory function in schizophrenia. Neuropsychopharmacology 26: 75-85.

Ghoneim M, Hinrichs J, Mewaldt S, Petersen R (1985). Ketamine: behavioral effects of subanesthetic doses. J Clin Psychopharmacol 5: 70-77.

Gold JM, Hahn B, Zhang WW, Robinson BM, Kappenman ES, Beck VM et al (2010). Reduced capacity but spared precision and maintenance of working memory representations in schizophrenia. Arch Gen Psychiatry 67: 570-577.

Granon S, Poucet B, Thinus-Blanc C, Changeux JP, Vidal C (1995). Nicotinic and muscarinic receptors in the rat prefrontal cortex: differential roles in working memory, response selection and effortful processing. Psychopharmacology (Berl) 119: 139-144.

Gray G, van den Buuse M, Scarr E (2009). Clozapine reverses schizophrenia-related behaviours in the metabotropic glutamate receptor 5 knockout mouse: association with N-methyl-Daspartic acid receptor up-regulation. Int J Neuropsychopharmacol 12: 45-60.

Groenewegen H, Uylings H (2000). The prefrontal cortex and the integration of sensory, limbic and autonomic information. Prog Brain Res 126: 3-28.

Jacobsen L, D’Souza D, Mencl W, Pugh K, Skudlarski P, Krystal J (2004). Nicotine effects on brain function and functional connectivity in schizophrenia. Biol Psychiatry 55: 850-858.

Javitt D (1999). Treatment of negative and cognitive symptoms. Curr Psychiatry Rep 1: 25-30.

Jedema HP, Moghddam B (1996). Characterization of excitatory amino acid modulation of dopamine release in the prefrontal cortex of conscious rats. J Neurochem 66: 1448-1453.

Kinoshita S, Yokoyama C, Masaki D (2008). Effects of rat medial prefrontal cortex lesions on olfactory serial reversal and delayed alternation tasks. Neurosci Res 60: 213-218.

Krystal J, Karper L, Seibyl J, Freeman G, Delaney R, Bremner J et al (1994). Subanesthetic effects of the noncompetitive NMDA antagonist, ketamine, in humans. Psychotomimetic, perceptual, cognitive, and neuroendocrine responses. Arch Gen Psychiatry 51: 199-214.

Krystal J, Perry EJ, Gueorguieva R (2005). Comparative and interactive human psychopharmacologic effects of ketamine and amphetamine: implications for glutamatergic and dopaminergic model psychoses and cognitive function. Arch Gen Psychiatry 62: 985-994. 
Laroche S, Davis S, Jay T (2000). Plasticity at hippocampal to prefrontal cortex synapses: dual roles in working memory and consolidation. Hippocampus 10: 438-446.

Laroche S, Jay T, Thierry A (1990). Long-term potentiation in the prefrontal cortex following stimulation of the hippocampal CA1/ subicular region. Neurosci Lett 114: 184-190.

Levin E (1992). Nicotinic systems and cognitive function. Psychopharmacology (Berl) 108: 417-431.

Levin E, Christopher N (2006). Effects of clozapine on memory function in the rat neonatal hippocampal lesion model of schizophrenia. Prog Neuropsychopharmacol Biol Psychiatry 30: 223-229.

Levin E, Kaplan S, Boardman A (1997). Acute nicotine interactions with nicotinic and muscarinic antagonists: working and reference memory effects in the 16-arm radial maze. Behav Pharmacol 8: 236-242.

Levin E, Kim P, Meray R (1996). Chronic nicotine effects on working and reference memory in the 16-arm radial maze: interactions with D1 agonist and antagonist drugs. Psychopharmacology (Berl) 127: 25-30.

Levin E, McClernon F, Rezvani A (2006). Nicotinic effects on cognitive function: behavioral characterization, pharmacological specification, and anatomic localization. Psychopharmacology (Berl) 184: 523-539.

Levin ED, Bettegowda C, Weaver T, Christopher NC (1998). Nicotine-dizocilpine interactions and working and reference memory performance of rats in the radial-arm maze. Pharmacol Biochem Behav 61: 335-340.

Levin ED, Rezvani AH (2006). Nicotinic-antipsychotic drug interactions and cognitive function. EXS 98: 185-205.

Luby E, Cohen B, Rosenbaum F, Gottlieb J, Kelley R (1959). Study of a new schizophrenomimetic drug, Sernyl. Arch Neurol Psychiatry 81: 363-369.

Malhotra A, Pinals D, Adler C, Elman I, Clifton A, Pickar D et al (1997). Ketamine-induced exacerbation of psychotic symptoms and cognitive impairment in neuroleptic-free schizophrenics. Neuropsychopharmacology 17: 141-150.

Malhotra A, Pinals D, Weingartner H (1996). NMDA receptor function and human cognition: the effects of ketamine in healthy volunteers. Neuropsychopharmacology 14: 301-307.

Meltzer H, McGurk S (1999). The effects of clozapine, risperidone, and olanzapine on cognitive function in schizophrenia. Schizophr Bull 25: 233-255.

Moghaddam B, Adams B, Verma A, Daly D (1997). Activation of glutamatergic neurotransmission by ketamine: a novel step in the pathway from NMDA receptor blockade to dopaminergic and cognitive disruptions associated with the prefrontal cortex. J Neurosci 17: 2921-2927.

Murphy B, Roth R, Arnsten A (1997). Clozapine reverses the spatial working memory deficits induced by FG7142 in monkeys. Neuropsychopharmacology 16: 433-437.

Murray JB (2002). Phencyclidine (PCP): a dangerous drug, but useful in schizophrenia research. J Psychol 136: 319-327.

Nabeshima T, Mouri A, Murai R, Noda Y (2006). Animal model of schizophrenia: dysfunction of NMDA receptor-signaling in mice following withdrawal from repeated administration of phencyclidine. Ann NY Acad Sci 1086: 160-168.

Newcomer J, Farber N, Jevtovic-Todorovic V (1999). Ketamineinduced NMDA receptor hypofunction as a model of memory impairment and psychosis. Neuropsychopharmacology 20: 106-118.
Newhouse PA, Potter A, Singh A (2004). Effects of nicotinic stimulation on cognitive performance. Curr Opin Pharmacol 4: 36-46.

Parwani A, Weiler M, Blaxton T, Warfel D, Hardin M, Frey K et al (2005). The effects of a subanesthetic dose of ketamine on verbal memory in normal volunteers. Psychopharmacology (Berl) 183: 265-274.

Patil S, Zhang L, Martenyi F, Lowe S, Jackson K (2007). Activation of mGlu2/3 receptors as a new approach to treat schizophrenia: a randomized Phase 2 clinical trial. Nature Medicine 13: 1102-1107.

Perala J, Suvisaari J, Saarni S, Kuoppasalmi K, Isometsä E, Pirkola S (2007). Lifetime prevalence of psychotic and bipolar I disorders in a general population. Arch Gen Psychiatry 64: 19-28.

Pocivavsek A, Laura Icenogle L, Levin E (2006). Ventral hippocampal $\alpha 7$ and $\alpha 4 \beta 2$ nicotinic receptor blockade and clozapine effects on memory in female rats. Psychopharmacology 188: $597-604$

Rorick-Kehn LM, Johnson BG, Knitowski KM, Salhoff CR, Witkin JM, Perry KW et al (2007). In vivo pharmacological characterization of the structurally novel, potent, selective mGlu2/3 receptor agonist LY404039 in animal models of psychiatric disorders. Psychopharmacology (Berl) 193: 121-136.

Rosenheck R, Dunn L, Peszke M (1999). Impact of clozapine on negative symptoms and on the deficit syndrome in refractory schizophrenia. Am J Psychiatry 156: 88-93.

Rushforth SL, Allison C, Wonnacott S, Shoaib M (2010). Subtypeselective nicotinic agonists enhance olfactory working memory in normal rats: a novel use of the odour span task. Neurosci Lett 471: 114-118.

Smith R, Singh A, Infante M, Khandat A (2002). Effects of cigarette smoking and nicotine nasal spray on psychiatric symptoms and cognition in schizophrenia. Neuropsychopharmacology 27: 479-497.

Smith R, Warner-Cohen J, Matute M, Butler E, Kelly E (2006). Effects of nicotine nasal spray on cognitive function in schizophrenia. Neuropsychopharmacology 31: 637-643.

Turchi J, Sarter M (2000). Cortical cholinergic inputs mediate processing capacity: effects of 192 IgG-saporin-induced lesions on olfactory span performance. Eur J Neurosci 12: 4505-4514.

Verma A, Moghaddam B (1996). The role of excitatory amino acids in prefrontal cortex function as assessed by spatial delayed alternation performance in rats: modulation by dopamine. J Neurosci 16: 373-379.

Weinberger D, Gallhofer B (1997). Cognitive function in schizophrenia. Int Clin Psychopharmacol 12: S29-S36.

Yoon T, Okada J, Jung M (2008). Prefrontal cortex and hippocampus subserve different components of working memory in rats. Learn Mem 19: 97-105.

Young JW, Crawford N, Kelly JS, Kerr LE, Marston HM, Spratt C et al (2007b). Impaired attention is central to the cognitive deficits observed in alpha 7 deficient mice. Eur Neuropsychopharmacol 17: 145-155.

Young JW, Kerr LE, Kelly JS, Marston HM, Spratt C, Finlayson K et al (2007a). The odour span task: a novel paradigm for assessing working memory in mice. Neuropharmacology 52: 634-645.

Zabala A, Eguiluz JI, Segarra R, Enjuto S, Ezcurra J, Pinto AG et al (2009). Cognitive performance and cigarette smoking in first-episode psychosis. Eur Arch Psychiatry Clin Neurosci 259: 65-71. 